\title{
An audit of obese patients on the renal transplant waiting list at University Hospital Birmingham
}

\author{
$T$ Nieto, C Pattenden
}

\section{Introduction}

- $\quad$ Renal transplantation improves outcome for ESRF patients ${ }^{(1)}$

- $\quad$ Patients with $\mathrm{BMI}>30$

- $\quad$ Present technical difficulties

- Increased chance of post operative complications ${ }^{(2-4)}$

- Decreased 5 year graft survival ${ }^{(5,6)}$

- $\quad$ Patients with $\mathrm{BMI}>40$ less likely to benefit from renal transplantation ${ }^{(1)}$

\section{7 year graft survival in obese vs non-obese} transplant recipients

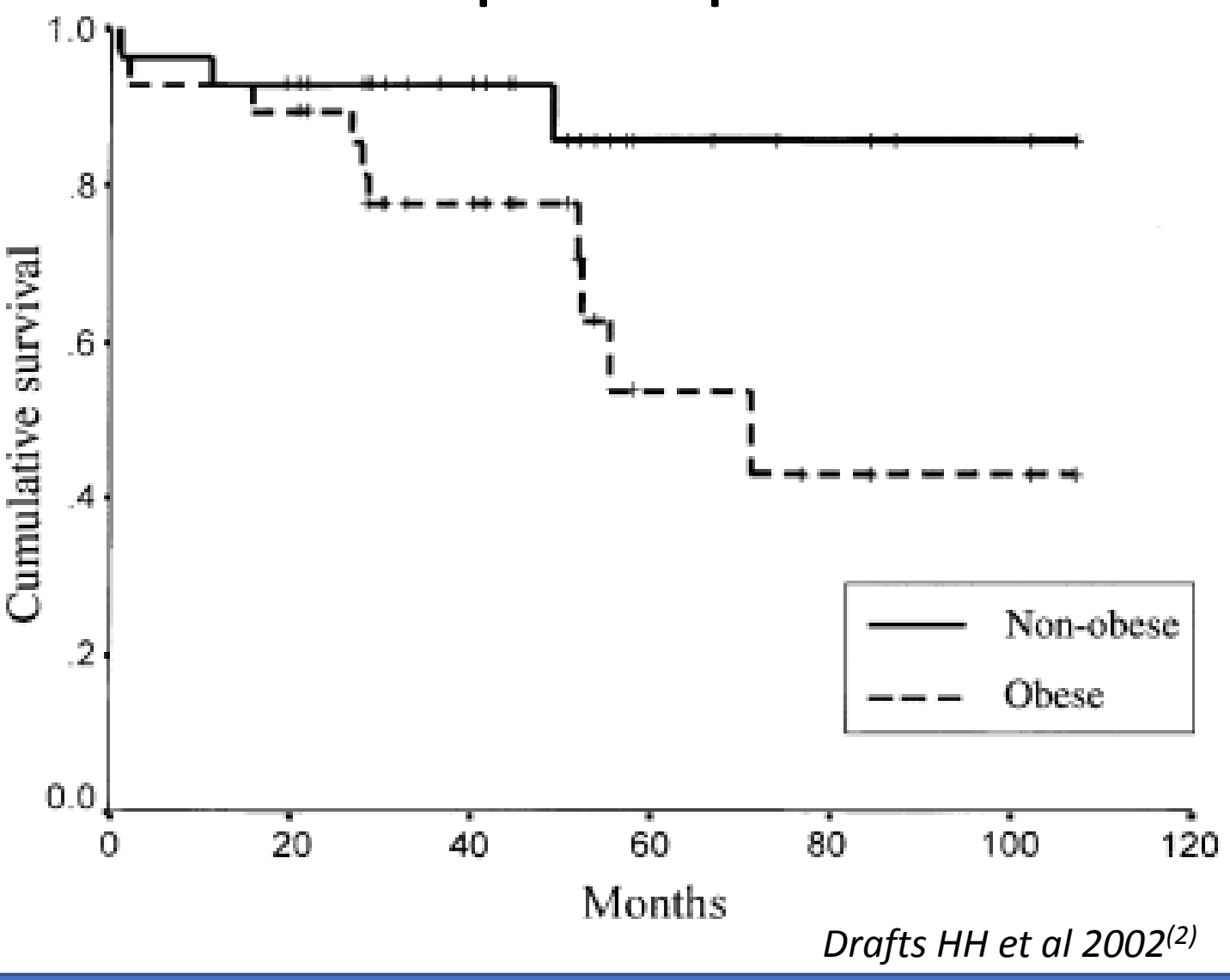

Method

Snapshot Audit $8^{\text {th }}$ June 2016

All active and suspended waiting list patients included All patients receiving renal replacement therapy included

$$
\text { Age }<65
$$$$
\mathrm{BMI}>30
$$

Clinical portal records examined for comorbidity

\section{Secondary Outcome}

- $\quad 157$ patients with $\mathrm{BMI}>35$

- $\quad 46$ patients identified whose only barrier to transplantation was elevated $\mathrm{BMI}$

$26 \%(n=13)$ had documented evidence of referral to specialist weight management services.
Graph showing trend in creatinine post renal transplantation BMI - Group A $<18.5$, Group E $>35$

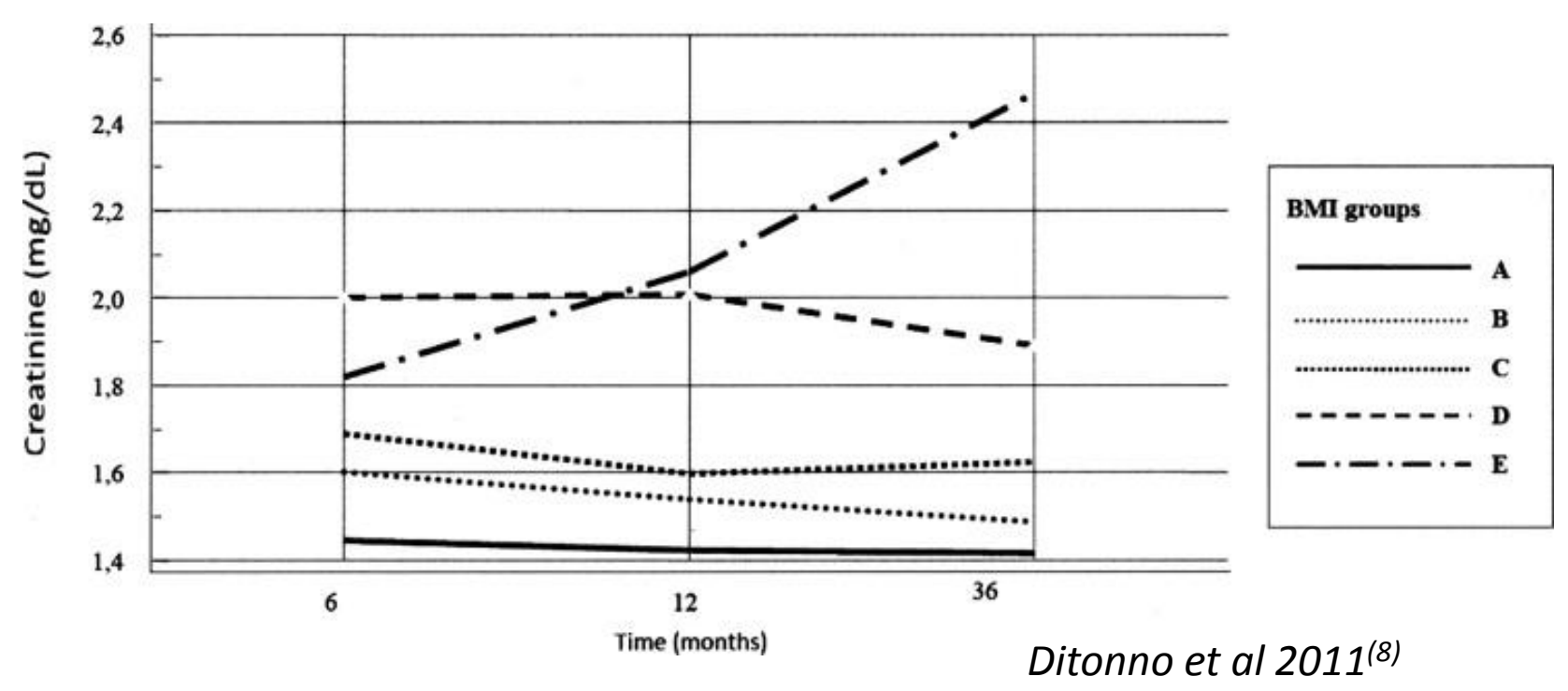

\section{Audit Aim}

To audit active and suspended renal transplant patients against Renal Association guidelines for listing morbidly obese patients.

"The number of patients with $B M I>40 \mathrm{~kg} / \mathrm{m}^{2}$ who are on the transplant waiting list and the reason for their inclusion." (7)

\section{Audit Outcome Measures}

Primary Outcome: Patients active on the waiting list with $\mathrm{BMI}>40$ should have a documented reason for listing.

Secondary Outcome: All renal patients with $\mathrm{BMI}>35$ should be referred to specialist weight management services (SWMS) if transplantable.

\section{Primary Outcome}

\begin{tabular}{l|l|l|}
\hline $\begin{array}{l}\text { Number of } \\
\text { patients }\end{array}$ & Active & Suspended \\
\hline $\begin{array}{l}\text { Mean BMI } \\
\begin{array}{l}\text { Percentage of } \\
\text { obese patients }\end{array}\end{array}$ & 27.16 & 303 \\
$\begin{array}{l}\text { Number of } \\
\text { patients with BMI } \\
>40\end{array}$ & 0 & 27.59 \\
\hline \begin{tabular}{l} 
Conclusion \\
\hline
\end{tabular} & & $30.7 \%$ \\
\hline
\end{tabular}

- UHB meets the guidelines for wait-listing patients with $\mathrm{BMI}>40$

- Small numbers of patients with documented referral to specialist weight management services

- Potentially delaying or excluding this group from future transplantation

References

1. Glanton CW, Kao TC, Cruess D et al. Impact of renal transplantation on survival in end-stage renal disease patients with elevated body mass index. Kidney Int 2003;63(2):647-53

2. Drafts HH, Anjum MR, Wynn JJ et al. The impact of pre-transplant obesity on renal transplant outcomes. Clin Transplant 1997;11:493-96

3. Howard RJ, Thai VB, Patton PR et al. Obese kidney transplant recipients have good outcomes. Transplant Proc 2001;33:3420-3421

Lynch RL, Ranney DN, Shijie C et al. Obesity, surgical site infection and outcome following renal transplantation. Ann Surgery 2009;250:1014-1020.

Yamamoto S, Hanley E, Hahn AB et al. The impact of obesity in renal transplantation: an analysis of paired cadaver kidneys. Clin Transplant2002;16(4):252-56 Gore JL, Pham PT, Danovitch GM et al. Obesity and outcome following renal transplantation. Am J Transplant 2006;6:357-63

Renal Association Guideline "Assessment of the Potential Kidney Transplant Recipient" 2010 http://www.renal.org/guidelines/modules/assessment-of-the-potentialkidney-transplant-recipient

Ditonno, P., et al., Obesity in Kidney Transplantation Affects Renal Function But Not Graft and Patient Survival. Transplantation Proceedings. 2011 43(1): p. 367-372. 